\title{
Prevalence and factors associated with Trichomonas vaginalis infection among pregnant women attending public antenatal clinics in Mwanza city, North-western Tanzania
}

AUGUSTINO J. MAUFI ${ }^{1}$, HUMPHREY D. MAZIGO ${ }^{2 *}$ and ALBERT KIHUNRWA ${ }^{1}$

${ }^{1}$ Department of Obstetrics and Gynaecology, School of Medicine, Catholic University of Health and Allied Sciences, Mwanza, Tanzania.

2Department of Medical Parasitology \& Entomology, School of Medicine, Catholic University of Health and Allied Sciences, P.O. Box 1464, Mwanza, Tanzania

\begin{abstract}
Background: Trichomonas vaginalis is a sexually transmitted parasitic infection known to cause vaginitis especially in women of child bearing age. The objective of this study was to determine the prevalence and factors associated with $T$. vaginalis among pregnant women attending public health facilities in Mwanza City, Tanzania.

Methods: This cross sectional study was conducted among pregnant women aged 17-46 years attending three public antenatal clinics in Mwanza City, north-western Tanzania. Wet preparation and Giemsa stained thick smears techniques were used to diagnose T. vaginalis infection. Sociodemographic characteristics and other risk related behaviours were collected.

Results: A total of 365 pregnant women participated in this study, 38 (10.41\%) and 84 (23.01\%) of them had trichomoniasis based on wet preparation and Giemsa stained thick smears respectively. On multivariable analysis, being HIV seropositive ( $A O R=11.65,95 \% \mathrm{Cl} ; 1.15-117.49, P<0.03)$ and having other sexual transmitted disease such as syphilis ( $A O R=4.40,95 \% \mathrm{Cl}: 1.32-14.7, P<0.01$ ) were significantly associated with $T$. vaginalis.

Conclusion: The prevalence of T. vaginalis in pregnant women in Mwanza city is high and the infection is associated with sexually transmitted diseases such as syphilis and HIV. Routine screening of $T$. vaginalis during ante-natal care clinics is highly recommended to reduce pregnancy complications related to T. vaginalis infection.
\end{abstract}

Keywords: Trichomonas vaginalis, pregnant women, Tanzania

\section{Introduction}

Trichomonas vaginalis is an anaerobic, flagellated protozoan parasite and the only protozoan parasite which is transmitted sexually between sexual partners (Schwebke and Burgess, 2004). Humans are the only known definitive host of the parasite and infected individuals harbour the trophozoite stage of the parasite (Schwebke \& Burgess, 2004). Female individuals are more likely to present with symptoms of the disease than male individual (WHO, 2001; Newman, 2015). In symptomatic male individuals, the infection is mainly characterized by irritation of the urethra, mild discharges and slight burning after urination or ejaculation (Schwebke \& Burgess, 2004). In symptomatic female individuals, T. vaginalis infection is characterized by green-yellowish frothy vaginal discharge, irritation of the vulva, itching, pain during urination, strawberry punctuate haemorrhagic lesion of the cervix and pain during coitus (Wølner-Hanssen et al., 1989).

Neonates can acquire infection through infected birth canal in an infected pregnant mother (Cotch, 1997). According to World Health Organization (WHO), an estimated 174 million cases of trichomoniasis are reported annually and this account for about $10-25 \%$ of vaginal infections (Poole \& McClelland, 2013). The prevalence of T. vaginalis during pregnancy are estimated to be as high as $41 \%$ in South Africa, 34\% in Tanzania and $9.9 \%$ in Central Republic of Africa (Cotch, 1997). Studies have shown that there is a link between T. vaginalis infection and

\footnotetext{
*Correspondence E-mail:- humphreymazigo@gmail.com
} 
increase risk of preterm birth and premature rupture of membrane (Draper et al., 1995; Swadpanich et al., 2008). These complications are suggested to be caused by inflammatory response directed against $T$. vaginalis infection which has an effect on reducing chorioamniotic membrane strength (Silver et al., 2014). A number of studies have shown that T. vaginalis infection is associated with low birth weight (Draper et al., 1995; Guenthner et al., 2005; Chinyere et al., 2012).

At present most developing counties use WHO guidelines for the syndromic treatment of sexually transmitted infections (STI) including $T$. vaginalis, whereby only pregnant women with signs and symptoms of T.vaginalis are treated (Petrin et al., 1998). This approach has been criticized as it leaves asymptomatic patients untreated (Romoren et al., 2007; Ademe et al., 2013). In pregnancy, the approach can be the source of serious complication of $T$. vaginalis infection, as many of the asymptomatic pregnant mothers will not be treated. In Tanzania, routine antenatal screening and treatment for $T$. vaginalis infection is not part of basic investigation list. Thus, there is a paucity of data on the prevalence and risk factors of $T$. vaginalis. In that context, the present study was designed to assess the prevalence, and risk factors associated with $T$. vaginalis infection among pregnant women attending ante-natal care clinics (ANC) in Mwanza city, northwestern Tanzania.

\section{Materials and Methods}

\section{Study area}

This study was conducted in Mwanza city, north-western Tanzania. Pregnant women attending ante-natal care clinics at Nyamagana hospital and Makongoro and Igombe Health Centres. While Nyamagana and lgombe are within the City, lgombe Health centre is located in peri-urban areas, about $20 \mathrm{~km}$ from Mwanza city centre and serves mainly the fishing communities. The selection of the ante-natal care clinics was based on the fact that these facilities serve a large number of pregnant women compared to others.

\section{Study design, population and inclusion criteria}

This cross-sectional study was conducted form November 2014 to April 2015. All pregnant women attending the ANC during the study period were eligible for inclusion and only those who gave written informed consent were included and examined. On the other hand, pregnant women were excluded in the study if they presented with per vaginal bleeding, genital pathology such as carcinoma of cervix, premature rupture of the membranes and had history of using metronidazole in the past one week.

\section{Sample size and sampling procedures}

The sample size was determined using statistical formula $\left(N=Z^{2} P(1-P) / d^{2}\right)$, where: $N=$ estimated sample size, $Z$ is critical value (1.96) at $95 \%$ confidence level, $P$ is an expected prevalence (32\%) and $\mathrm{d}$ is precision or margin of error (5\%). A minimum sample size $(\mathrm{N})$ of 334 pregnant women was obtained. Convenient sampling was used to select pregnant women, in which all pregnant women who met the inclusion criteria were serially enrolled until the required sample size was reached.

\section{Data collection methods}

A pre-tested questionnaires was used to collected information on socio-demographic characteristics, gynaecological and obstetric history such as gravidity, parity, previous history of ANC attendance, age of pregnancy in weeks, age of pregnancy at initial ANC attendance, number of ANC attended in the entire gestation period and whether or not the woman was ever screened for T. vaginalis. Any pregnancy related complication(s) were also enquired and recorded. 
Antenatal cards were reviewed to obtain information on other investigations such as HIV or syphilis screening done during the ANC visits.

Study participants were examined in the lithotomy position; a sterile Cusco speculum was inserted into the vagina and specimen was collected from vaginal walls (lateral interior and posterior) using a sterile swab sticks(Houso et al., 2011). The swabs were rotated 10 to 30 seconds in the vaginal walls to allow it to absorb fluids. After collection of specimen, the swabs were stored in a bottle containing a Stuart Transport Medium and transported to the laboratory for immediate investigation at the Catholic University of Health and Allied Sciences in Mwanza. In the laboratory, a wet preparation using microscopic glass slides was prepared using a $0.85 \%$ normal saline and examined microscopically for the presence of T. vaginalis trophozoites. Conversely, a thick smears were prepared from vaginal swabs, allowed to dry at room temperature (for 15-20 minutes), stained with 3\% Giemsa stains and examined microscopically for the presence of trophozoites by two independent medical laboratory technicians (Houso et al., 2011). For quality assurance, $10 \%$ of the positive and negative Giemsa stained thick smears were re-examined by a third medical laboratory technician.

\section{Data analysis}

Data were double entered, verified and cleaned using MS Excel spread sheet and were transferred to Stata version 13 for analysis (Stata Corp, USA). Categorical data were described using Chi-square test $\left(\chi^{2}\right)$ or Fishers exact test, where appropriate. Student T-test was used to describe continuous variables. To determine the factors associated with $T$. vaginalis infection, bivariate logistic regression model was developed and used, all factors with $P=0.2$ were considered for multivariable logistic regression. Significant association was considered when $P$ values was $<0.05$.

\section{Ethical considerations}

Ethical approval was sought from the Catholic University of Health and Allied Sciences/Bugando Medical Centre Research Ethics Committee. Informed consent was sought and obtained from all study participants. For study participants aged $<18$ years, consent was thought from parents/guardians and the participants themselves gave written assent. Patient diagnosed to have $T$. vaginalis infection were treated according to national treatment guidelines.

\section{Results}

\section{Socio-demographic characteristics}

A total of 365 pregnant women were recruited. Of these, 94 (25.75\%) were from Nyamagana, 106 (29.04\%) from lgombe and 165 (45.21\%) were from Makongoro. The median age of the study participants was 26 years (range: $17-46$ years) with $53 \%$ of the study participants aged between 13 - 25 years. Of these pregnant women, $92 \%$ reported to be married and $71 \%$ were living in urban area. About two-thirds (66\%) of the study participants had attained primary school education. The majority of participants (88\%) were in their third trimester, having the gestation age of 26-37 weeks and $53 \%$ were in para $1-3$ (Table 1 ).

\section{Prevalence of $\mathrm{T}$. vaginalis}

The prevalence of $T$. vaginalis infection was $10.4 \%$ by wet preparation technique and was $23.01 \%$ by Giemsa stain. The prevalence of T. vaginalis infection was high in several social demographic (Table 1) and obstetric characteristics of the study participants (Table 2). 
Table 1: Prevalence of T. vaginalis infection in relation to socio-demographic characteristics

\begin{tabular}{|c|c|c|c|c|c|}
\hline \multirow[t]{2}{*}{ Variable } & \multirow[t]{2}{*}{ Responses } & \multicolumn{2}{|c|}{ T. vaginalis Positive } & \multicolumn{2}{|c|}{ T. vaginalis Negative } \\
\hline & & Number & Percent & Number & Percent \\
\hline \multirow[t]{3}{*}{ Age (years) } & $15-25$ & 48 & 24.7 & 146 & $75 \cdot 3$ \\
\hline & $26-35$ & 32 & 22.9 & 108 & 77.1 \\
\hline & $36-46$ & 4 & 12.9 & 27 & 87.1 \\
\hline \multirow[t]{4}{*}{ Marital status } & Single & 5 & 26.3 & 14 & 73.7 \\
\hline & Cohabiting & 1 & 10.0 & 9 & 90 \\
\hline & Married & 77 & 23.1 & 257 & 77 \\
\hline & Separated & 1 & 50 & 1 & 50 \\
\hline \multirow[t]{2}{*}{ Residence } & Urban & 54 & 20.9 & 205 & 79.2 \\
\hline & Rural & 30 & 28.3 & 76 & 71.7 \\
\hline \multirow[t]{2}{*}{ Education level } & Literate & 77 & 23.2 & 255 & 76.8 \\
\hline & Illiterate & 7 & 21.2 & 26 & 78.8 \\
\hline \multirow[t]{3}{*}{ Occupation } & Employed & 38 & 24.1 & 120 & 76 \\
\hline & Peasant & 21 & 26.9 & 57 & 73.1 \\
\hline & Unemployed & 25 & 19.4 & 104 & 80.6 \\
\hline
\end{tabular}

Table 2: Prevalence of $T$. vaginalis infection in relation to obstetric characteristics

\begin{tabular}{llll}
\hline Variable & Response & $\begin{array}{l}\text { Trichomonas vaginalis } \\
\text { Positive, N(\%) }\end{array}$ & Negative, N(\%) \\
\hline Gravidity & 1 & $24(20.2)$ & $95(79.8)$ \\
& $2-3$ & $34(25.4)$ & $100(74.6)$ \\
Gestation age (weeks) & $\geq 4$ & $26(23.2)$ & $86(79.8)$ \\
& $13-25$ & $5(17.7)$ & $23(82.1)$ \\
Parity & $26-37$ & $78(24.4)$ & $242(75.6)$ \\
& $38-42$ & $1(5.9)$ & $16(94.1)$ \\
& 0 & $26(20.6)$ & $100(79.4)$ \\
& $1-3$ & $44(22.6)$ & $151(77.4)$ \\
& $\geq 4$ & $14(31.8)$ & $30(68.2)$ \\
\hline
\end{tabular}

\section{Risk factors associated with $T$. vaginalis infection}

At bivariate analysis, factors significantly associated with $T$. vaginalis were sharing of bathroom $(\mathrm{OR}=8.82,95 \% \mathrm{Cl} ; 1.18-65.93, \mathrm{P}<0.034)$ and reported use of shared toilet $(\mathrm{OR}=7.7,95 \% \mathrm{Cl} ; 1.03-$ 58.17; $P<0.054)$. Symptoms such as vaginal discharge $(\mathrm{OR}=2.10 ; 95 \% \mathrm{Cl} ; 1.20-3.70, \mathrm{P}<0.01)$, vaginal itching (OR=2.16, 95\% Cl; 1.31-3.55, $P<0.002)$ and vulva ulceration $(\mathrm{OR}=2.36,95 \% \mathrm{Cl} ; 1.24-4.52$, $P<0.01)$ were also associated with $T$. vaginalis infection. Other factors significantly associated with $T$. vaginalis at bivariate analysis were being HIV seropositive $(\mathrm{OR}=7.15 ; 95 \% \mathrm{Cl} ; 1.28-39.86 ; P<0.03)$, having history of being infected with other sexually transmitted infections such as syphilis during pregnancy (OR=3.30, 95\% Cl; 1.11- 9.77, $\mathrm{P}<0.031$ ) (Table 3). In multivariable analysis, being HIV seropositive ( $A O R=11.65,95 \% \mathrm{Cl} ; 1.15-117.49, P<0.03)$ and having other sexually transmitted infections $(A O R=4.40,95 \% \mathrm{Cl}: 1.32-14.7, P<0.01)$ were the only factors associated with $T$. vaginalis infection.

Table 3: Bivariate analysis on risk factors associated with T. vaginalis infection

\begin{tabular}{llllll}
\hline Variable & Response & Positive & Negative & Crude OR [95\%Cl] & P-value \\
\hline Age group (years) & $15-25$ & $48(24.74 \%)$ & $146(75.26)$ & 1 & \\
& $26-35$ & $32(22.86 \%)$ & $108(77.14 \%)$ & $0.90[0.55-1.49]$ & 0.70 \\
& $36-46$ & $4(12.90 \%)$ & $27(87.10 \%)$ & $0.32[0.72-1.43]$ & 0.13 \\
Marital status & Married & $77(23.05 \%)$ & $257(76.95 \%)$ & 1 & \\
& Single & $6(28.57 \%)$ & $15(71.43 \%)$ & $1.33[0.50-3.55]$ & 0.56 \\
\multirow{2}{*}{ Residence } & Cohabiting & $1(10.0 \%)$ & $9(90.0 \%)$ & $0.37[0.04-2.97]$ & 0.30 \\
& Rural & $30(28.30 \%)$ & $76(71.70 \%)$ & 1 & \\
& Urban & $54(20.85 \%)$ & $205(79.15 \%)$ & $0.66[0.39-1.12]$ & 0.12
\end{tabular}




\begin{tabular}{|c|c|c|c|c|c|}
\hline \multirow[t]{3}{*}{ Gravidity } & 1 & $24(20.17 \%)$ & $95(79.83 \%)$ & 1 & \\
\hline & $2-3$ & $34(25.37 \%)$ & $100(74.67 \%)$ & $1.34[0.74-2.43]$ & 0.32 \\
\hline & $\geq 4$ & $26(23.21 \%)$ & $86(76.79 \%)$ & $1.19[0.63-2.23]$ & 0.57 \\
\hline \multirow[t]{3}{*}{ Parity } & 0 & $26(20.63 \%)$ & $100(79.37 \%)$ & 1 & \\
\hline & $1-3$ & $44(22.56 \%)$ & $151(77.44 \%)$ & $1.12[0.64-1.93]$ & 0.68 \\
\hline & $\geq 4$ & $14(31.82 \%)$ & $30(68.18 \%)$ & $1.79[0.83-3.86]$ & 0.13 \\
\hline \multirow[t]{2}{*}{ Sharing bathroom } & Yes & $83(24.63 \%)$ & $254(75.37 \%)$ & $8.83[1.18-65.9]$ & 0.03 \\
\hline & No & $1(3.35 \%)$ & $27(96.43 \%)$ & 1 & \\
\hline \multirow[t]{2}{*}{ Common toilet } & Yes & $83(24.41 \%)$ & $257(75.37 \%)$ & $7.75[1.03-58.1]$ & 0.04 \\
\hline & No & $1(4.00 \%)$ & $24(96.00 \%)$ & 1 & \\
\hline \multirow[t]{2}{*}{ Vaginal discharge } & Yes & $25(34.72 \%)$ & $47(65.28 \%)$ & $2.10[1.20-3.70]$ & 0.01 \\
\hline & No & $59(20.14 \%)$ & $234(79.86 \%)$ & 1 & \\
\hline \multirow[t]{2}{*}{ Vaginal itching } & Yes & $41(18.07 \%)$ & $47(65.28 \%)$ & $2.16[1.31-3.55]$ & 0.01 \\
\hline & No & $43(18.07 \%$ & $234(79.86 \%)$ & 1 & \\
\hline \multirow[t]{2}{*}{ Vulva ulceration } & Yes & $18(38.30 \%)$ & $29(61.70 \%)$ & $2.36[1.24-4.52]$ & 0.01 \\
\hline & No & $66(20.75 \%)$ & $252(79.25 \%)$ & 1 & \\
\hline \multirow[t]{2}{*}{ HIV status } & Negative & $71(21.85 \%)$ & $254(78.15 \%)$ & 1 & \\
\hline & Positive & $4(66.67 \%)$ & $2(33.33 \%)$ & $7[1.28-39.8]$ & 0.02 \\
\hline \multirow[t]{2}{*}{ Syphilis status } & Negative & $65(32.21 \%)$ & $215(76.79 \%)$ & 1 & \\
\hline & Positive & $7(50.00 \%)$ & $7(50.00 \%)$ & $3.30[1.11-9.77]$ & 0.03 \\
\hline
\end{tabular}

Key: OR=odd ratio

\section{Discussion}

The prevalence of T. vaginalis in this study was higher than many other studies elsewhere in SubSaharan Africa (Mairiga, 2011; Eshete, 2013; Lazenby et al., 2014). However, the prevalence was slightly lower than that reported by Iwueze et al. (2014) in Anambra, Nigeria. The variation in prevalence of $T$. vaginalis infection observed by these studies could be partly explained by different in sensitivity of methods used to diagnose $T$. vaginalis infection, different study population and differences in hygiene practices among the study population. Cultural and traditional practices such as polygamy may also explain the variation in the prevalence of $T$. vaginalis infection; with polygamy increases the risk of acquiring T. vaginalis (Iwueze et al., 2014)

In this study several risk factors were found to be associated with $T$. vaginalis. In multivariable analysis, sexually transmitted infection including HIV and syphilis was found to be associated with $T$. vaginalis. The observation that HIV was associated with $T$. vaginalis was consistent with the findings of a previous study by Van der Pol et al. (2008). Perhaps, the observed association partly may be explained by the fact that $T$. vaginalis infection may facilitate HIV transmission through disruption of genital epithelial, hence increases the risk of HIV transmission (Sorvillo et al., 2001). In addition, the association can be explained by the fact that having T.vaginalis may increase the risk of other ulcerative sexually transmitted infections, which are known to increase the risk of HIV transmission (Sorvillo et al., 2001). In this study, symptoms such as vaginal discharge, vaginal itching and vulval ulceration were significantly associated with $T$. vaginalis infection. These findings were consistent with the results of previous studies in Ethiopia (Eshete et al., 2013). Additional symptoms such as pain during urination and pain during coitus have also been described to be associated with T. vaginalis (Fernando et al., 2012).

The present study is subject to limitations. This was a cross-sectional study and therefore, a temporal relationship between outcome and other associated factors could not be realized. In addition, the methods used for diagnosis of $T$. vaginalis are less sensitive in detecting $T$. vaginalis infection, thus, more sensitive diagnostic techniques such as culture and polymerase chain reaction (PCR) are recommended in future studies.

In conclusion, the prevalence of $T$. vaginalis in pregnant women attending selected ANC in Mwanza city is high and the infection is associated with sexually transmitted infections. Routine 
screening of $T$. vaginalis during ante-natal care clinics is highly recommended to reduce the pregnancy complications related to $T$. vaginalis infection.

\section{References}

Ademe, M., Kebede, T., Fikrie, N. \& Merawi, A.R.S. (2013) Syndromic management approach and wet mount microscopy of Trichomonas vaginalis in pregnant women and sexually transmitted infection clinic attendants in Merawi Health Center, Merawi, Amhara Regional State. International Sexual Transmitted Diseases Research and Reviews, 1, 30-38.

Chinyere, E., Romanus, I.I., Collins, O.N., Okoro, N., Anthonia, O.J.I.E. \& Biological, F.O.F. (2012) Trichomonas vaginalis associated with adverse pregnancy outcomes. British Journal of Medical Research 2, 568-574.

Cotch, M.F. (1997) Trichomonas vaginalis associated with low birthweight and premature delivery. Sexually Transmitted Diseases 24, 353-360.

Draper, D., Jones, W., Heine, R.P., Beutz, M., French, J.I. \& McGregor, J.A. (1995) Trichomonas vaginalis weakens human amniochorion in an in vitro model of premature membrane rupture. Infectious Diseases in Obstetrics and Gynaecology 2, 267-74.

Eshete, A., Mekonnen, Z. \& Zeynudin, A. (2013) Trichomonas vaginalis infection among pregnant women in Jimma University Specialized Hospital, Southwest Ethiopia. International Scholar Research Notices Infectious Diseases 5. ID 485439.

Fernando, S.D., Herath, S., Rodrigo, C. \& Rajapakse, L. (2012) Clinical features and sociodemographic factors affecting Trichomonas vaginalis infection in women attending a central sexually transmitted diseases clinic in Sri Lanka. Indian Journal of Sexually Transmitted Infection 33, 25-31.

Guenthner, P.C., Secor, W.E. \& Dezzutti, C.S. (2005) Trichomonas vaginalis-induced epithelial monolayer disruption and human immunodeficiency virus type 1 (HIV-1) replication: implications for the sexual transmission of HIV-1. American Society for Microbiology 73, 4155-4160.

Houso, Y., Farraj, M.A., Ramlawi, A. \& Essawi, T. (2011) Detection of Trichomonas vaginalis in vaginal swab clinical samples from Palestinian women by culture. ISRN Microbiology ID 872358.

Iwueze, M.O., Ezeanyanwu, L.N., Okafor, F.C., Nwaorgu, O.C. \& Ukibe, S.C. (2014) Prevalence of Trichomonas vaginalis infection among women attending hospitals/health centres in Onitsha community, Onitsha North Local Government Area of Anambra State. Bioscientist 2, 54-64.

Lazenby, G.B., Taylor, P.T., Badman, B.S., Mchaki, E., Korte, J.E., Soper, D.E. \& Young Pierce, J. (2014) An association between Trichomonas vaginalis and high-risk human papillomavirus in rural Tanzanian women undergoing cervical cancer screening. Clinical Therapeutics 36, 38-45.

Mairiga, A.G., Balla, H.J. \& Ahmad, M.I. (2011) Prevalence of Trichomonas vaginalis infections among antenatal clients in Maiduguri, Nigeria. International Journal of Biological and Medical Research 2, 998-1002.

Newman, L., Rowley, J., Vander Hoorn, S., Wijesooriya, N.S., Unemo, M., Low, N., Stevens, G., Gottlieb, S., Kiarie, J. \& Temmerman, M. (2015) Global estimates of the prevalence and incidence of four curable sexually transmitted infections in 2012 based on systematic review and global reporting. PLoS One 10, e0143304.

Petrin, D., Delgaty, K., Bhatt, R. \& Garber, G. (1998) Clinical and microbiological aspects of Trichomonas vaginalis. Clinical Microbiology Reviews 11, 300-317.

Poole, D.N. \& McClelland, R.S. (2013) Global epidemiology of Trichomonas vaginalis. Sexually Transmitted Infections 89, 418-422. 
Romoren, M., Velauthapillai, M., Rahman, M., Sundby, J., Klouman, E. \& Hjortdahl, P. (2007) Trichomoniasis and bacterial vaginosis in pregnancy: inadequately managed with the syndromic approach. Bulletin the World Health Organization 85, 297-304.

Schwebke, J.R. \& Burgess, D. (2004) Trichomoniasis. Clinical Microbiology Reviews 17, 794-803.

Silver, B.J., Guy, R.J., Kaldor, J.M., Jamil, M.S. \& Rumbold, A.R. (2014) Trichomonas vaginalis as a cause of perinatal morbidity: a systematic review and meta-analysis. Sexually Transmitted Diseases 41, 369-76.

Sorvillo, F., Smith, L., Kerndt, P. \& Ash, L. (2001) Trichomonas vaginalis, HIV, and AfricanAmericans. Emerging Infectious Diseases 7, 927-32.

Swadpanich, U., Lumbiganon, P., Prasertcharoensook, W. \& Laopaiboon, M. (2008) Antenatal lower genital tract infection screening and treatment programs for preventing preterm delivery. Cochrane Database Systematic Review 2, CDo06178.

Van Der Pol, B., Kwok, C., Pierre-Louis, B., Rinaldi, A., Salata, R.A., Chen, P.L., Van de Wijgert, J., Mmiro, F., Mugerwa, R., Chipato, T. \& Morrison, C.S. (2008) Trichomonas vaginalis infection and Human Immunodeficiency Virus acquisition in African women. Journal of Infectious Diseases 197, 548-554.

WHO (2001) Global prevalence and incidence of selected curable sexually transimitted infections. Sexual Transmitted Diseases, 2001, 1-50.

Wølner-Hanssen, P., Krieger, J.N., Stevens, C.E., Kiviat, N.B., Koutsky, L., Critchlow, C., Derouen, T., Hillier, S. \& Holmes, K.K. (1989) Clinical manifestations of vaginal trichomoniasis. JAMA 261, 571-576. 